\title{
Grand Challenges in Emerging Separation Technologies
}

\author{
Lu Shao* \\ MIIT Key Laboratory of Critical Materials Technology for New Energy Conversion and Storage, School of Chemical \\ Engineering and Technology, State Key Laboratory of Urban Water Resource and Environment, Harbin Institute of \\ Technology, Harbin, China
}

Keywords: emerging separation technology, challenges, environmental remediation, membranes, advanced applications, energetic-efficient process

With the development of society, a large amount of liquid waste is generated in the chemical, pharmaceutical, and printing industry and also in daily life. However, the liquid waste also contain some useful chemicals. What is more, the treatment of liquid waste and the separation and recycling of useful substances are of great significance. For example, as of 2014, the amount of untreated organic liquid waste is $\sim 2.7$ million tons per year, which causes an economic loss of 530 billion US dollars (Cseri et al., 2018). Traditional separation technologies, such as multistage distillation, temperature swing adsorption, and azeotropic distillation, have a large carbon footprint, which undoubtedly increases the processing costs. Furthermore, with the tremendous interest in separation technologies, people are driven to search for low energy consumption separation technologies which are independent of phase changes of fluids (Sholl and Lively, 2016; Lively and Sholl, 2017). For example, advanced membrane separation technology enables such a green process that can greatly reduce the energy consumption and carbon, which is able to pace the intensity of conventional distillation processes for the separation and purification of compounds (Jimenez-Solomon et al., 2016; Liu et al., 2016; Wang et al., 2018, 2019; Zhang et al., 2019). Significantly, the energy consumption per liter in the emerging membrane separation process is about $1 / 25$ times as much as that in the conventional distillation process (Rundquist et al., 2012; Yang et al., 2020).

Although emerging separation technologies save energy, it is very difficult to replace traditional separation technologies completely due to large-scale production and imperfect development (Cuperus and Smolders, 1991; Wang et al., 2006, 2012; Striemer et al., 2007; Feng et al., 2016). At present, we are in an era where emerging and traditional separation technologies have to be replaced. In addition, it is necessary to summarize the current common problems in the field of separation, which is of little significance for saving resources and achieving sustainable development. Based on this, this article aims to analyze the problems in the currently important separation process, with a view to point out the research path for emerging separation technologies to replace traditional separation technologies.

Specialty section: This article was submitted to Separation Technologies, a section of the journal Frontiers in Environmental Chemistry

Received: 24 March 2020 Accepted: 24 April 2020 Published: 26 May 2020

Citation: Shao L (2020) Grand Challenges in Emerging Separation Technologies.

Front. Environ. Chem. 1:3. doi: 10.3389/fenvc.2020.00003

\section{WASTEWATER TREATMENT AND RECYCLING}

The traditional sewage treatment is mainly through Anoxic Oxic (AO) and Anaerobic-AnoxicOxic $\left(\mathrm{A}^{2} \mathrm{O}\right)$ processes (an activated sludge method). However, traditional treatment techniques often result in poor effluent quality due to unstable activated sludge in the secondary sedimentation tank. The appearance of the membrane (membrane bio-reactor technology) laid a foundation for solving this problem. Using the membrane separation, a high-efficiency sludge-water separation is realized, and the effluent quality is greatly improved (Kang et al., 2018). However, in this process, membrane fouling led to a significant reduction in the membrane life and increases the processing costs. In addition, in order to meet drinking water standards, it is often necessary to further remove contaminants from the effluent. 
For the posttreatment of the effluent, traditional separation technologies include mainly desalination such as distillation. Although distillation is the most effective separation technology, the required high energy consumption is 50 times more than the minimum energy, which is required to produce drinking water from seawater according to the thermodynamic definition (Zhang Y. et al., 2020), thereby driving people to find more suitable processing technologies.

A reverse osmosis (RO) membrane separation technology is an excellent candidate. The energy consumption is significantly reduced, which accounts for only $\sim 25 \%$ of the thermodynamic minimum energy (Koros and Lively, 2012; Zhang Y. et al., 2020) because this separation process does not have the occurrence of the phase conversion. However, the permeance of the RO membranes is very low under applied pressure of less than $2 \mathrm{~L}$ $\mathrm{m}^{-2} \mathrm{~h}^{-1}$ bar $^{-1}$, which leads to inefficient water treatment (Lee et al., 2011). To increase permeance, roll membrane modules were introduced into the treatment process to improve the effective membrane penetration area, which caused an increase in the water treatment costs. Furthermore, when RO membranes are used for treating high-concentration effluents such as high salt or suspended matter wastewater, the performance of RO membranes decreases drastically due to membrane fouling. Therefore, in the actual application, a single RO membrane separation system is very difficult to deal with the effluent, which inevitably needs to use an integrated system to achieve the best treatment effect. However, the integrated system is not a longterm consideration. It is an urgent need to develop budget RO membranes demonstrating excellent performance to improve the possibility of running of the original RO system.

In summary, it is important to reduce the operating costs that the development of high permeance, inexpensive, and pollutionresistant $\mathrm{RO}$ membranes, which is conducive to the commercial feasibility of the technology even in the treatment of highly polluted water bodies.

\section{GREENHOUSE GAS CAPTURE}

Greenhouse gas mainly includes carbon dioxide, nitrous oxide, methane, and freons (Gorham, 1991; Kasimir-Klemedtsson et al., 2010). Among them, carbon dioxide emissions contribute the most to environmental hazards, accounting for 25\% (Khalilpour et al., 2015). Carbon dioxide is mainly produced by burning coal, oil, and natural gas, which is an indispensable energy source for economic development and social progress (Quadrelli and Peterson, 2007). There is no doubt that, before the spread of clean energy, carbon dioxide emissions will gradually increase. What is more, the capture of carbon dioxide is very important according to the protection of the environment and achieving sustainable development. A simple carbon dioxide capture technology is summarized in Table 1.

The energy consumption of traditional adsorbent adsorption and desorption is high (Rochelle, 2009), which is mainly due to the high temperature required for carbon dioxide desorption, because of the strong adsorption of carbon dioxide
TABLE 1 | Materials for gas capture.

\begin{tabular}{lll}
\hline Materials & Captured gas & References \\
\hline Amine Scrubbing & $\mathrm{CO}_{2}$ & Rochelle, 2009 \\
UTSA-16 MOFs & $\mathrm{CO}_{2}$ & Xiang et al., 2012 \\
$\begin{array}{l}\text { SPEEK, PEO and PIM flat } \\
\text { polymer membranes }\end{array}$ & $\mathrm{CO}_{2}$ & Adewole et al., 2013 \\
$\begin{array}{l}\text { PVDF, PP and PTFE Hollow fiber } \\
\text { membranes }\end{array}$ & $\mathrm{CO}_{2}$ & Ze and Sx, 2014 \\
ZIF-8 based ceramic membrane & $\mathrm{CO}_{2}$ & Jiang et al., 2019 \\
\hline
\end{tabular}

and adsorbent. For example, using this technology to capture carbon dioxide from flue gas consumes $30 \%$ of the energy of the power plant (Haszeldine, 2009). In addition, the corrosiveness of the adsorbent will also cause secondary pollution to the environment (Xiang et al., 2012). Therefore, it is necessary to develop a low-cost carbon dioxide capture technology.

Emerging membrane separation technologies can effectively reduce costs because no heating is required during processing (Ze and Sx, 2014). For example, a hollow fiber membrane gas capture technology has been widely used in industrial sectors and laboratories (Ze and Sx, 2014). Similarly, examples include Jiang et al. (2019) who observed that a ZIF-8-based ceramic membrane demonstrated excellent capture performance for $\mathrm{CO}_{2}$, opening a new chapter (organic-inorganic hybrid gas capture membrane), which greatly promotes the application of a membrane separation technology due to excellent resistance of inorganic membranes. However, due to technical and economic issues, a membrane gas capture technology is difficult to achieve large-scale industrial applications. For large-scale applications, the challenges of a membrane gas capture technology mainly focus on the following aspects.

First of all, the design of the membrane structure and the choice of materials are key factors. It is necessary to develop high-temperature, corrosion-resistant, and pollutionresistant gas permeable membranes. In addition, the permeability and selectivity, mechanical properties, stability, and process compatibility need to be carefully considered. However, the existing research mainly focuses on the permeability of the gas membrane, and lacks consideration of other important factors. What is more, the impact of trace gas components (for example, $\mathrm{O}_{2}, \mathrm{SO}_{\mathrm{x}}, \mathrm{NO}_{\mathrm{x}}$, and $\mathrm{NH}_{3}$ ) on a membrane capture technology has been ignored in the existing articles and researches that focus on the separation of a binary mixture of $\mathrm{N}_{2}$ and $\mathrm{CO}_{2}$ (Adewole et al., 2013). In addition, it may not be feasible to use a single-stage membrane gas capture technology because of the low carbon dioxide content of the flue gas, even if the membrane demonstrates high permselectivities ( $\mathrm{Li}$ and Chen, 2005). Therefore, a multistage membrane gas capture technology may be feasible and at the same time improves the separation efficiency of carbon dioxide and product purity, which leads to an increase in the processing costs and an improvement of processing technology. In the conclusion, in the application of membrane contactors for gas absorption, the limitation of the trade-off between cost and performance is ultimately to be resolved. 
TABLE 2 | Materials for separation of dyes and salts from sewage.

\begin{tabular}{|c|c|c|}
\hline Materials & Methods & References \\
\hline $\mathrm{BiOCl}$ and $\mathrm{La}_{2} \mathrm{BiNbO}_{7}$ & Photocatalysis & Rochkind et al., 2015 \\
\hline $\begin{array}{l}\text { Activated rice husk, cedar } \\
\text { sawdust, crushed brick and } \\
\text { Activated carbon. }\end{array}$ & Absorption & Kandisa et al., 2016 \\
\hline $\begin{array}{l}\text { TiO2 based nanofiltration } \\
\text { membranes }\end{array}$ & Aperture screening & Cheng et al., 2017 \\
\hline graphene-based membranes & Aperture screening & $\begin{array}{l}\text { Yang et al., 2017; Gao } \\
\text { et al., } 2018\end{array}$ \\
\hline $\begin{array}{l}\text { UiO-66 based nanofiltration } \\
\text { membranes }\end{array}$ & Aperture screening & Huang et al., 2020 \\
\hline
\end{tabular}

Furthermore, how to deal with purified products is an important issue. Carbon dioxide can be used in the crude oil production and also in agricultural, chemical, and biological refining of feedstocks. However, humans emit large amount of gas that is stored in underground reservoirs for a long time, which causes many other problems.

\section{SEPARATION OF DYES AND SALTS FROM SEWAGE}

In recent years, dyes have been widely used in papermaking, printing, pharmaceutical, textile, and other industries (Crini and Badot, 2008). The discharge of colored sewage destroys the environment and endangers human health (Katheresan et al., 2018). In addition, in order to improve the adsorption of dyes in the product, inorganic salts (for example, $\mathrm{NaCl}$ and $\mathrm{Na}_{2} \mathrm{SO}_{4}$ ) are often added during the preparation process (Vreese and Bruggen, 2007; Wang et al., 2013; Lin et al., 2015; Zhu et al., 2016). Therefore, this kind of wastewater often includes dyes and salts that are valuable resources. However, in the progress of this wastewater, traditional separation technologies such as adsorption (Kandisa et al., 2016) and photocatalysis (Rochkind et al., 2015) are very complicated due to the existence of highly concentrated dyes/salts (Table 2). It is very urgent to develop a simple technology such as emerging membrane technology. However, some RO and nanofiltration membranes often separate dyes and salts at the same time by aperture screening and Donan effect. It is very difficult to achieve the separation of dyes and salts, respectively. The emergence of loose nanofiltration membranes laid a foundation for solving this problem.

Currently, the two main preparation methods of loose nanofiltration membranes are nanoparticle-based in situ polymerization (Cheng et al., 2017; Huang et al., 2020) and two-dimensional (2D) material nanofiltration membranes (Yang et al., 2017; Gao et al., 2018). By the way, the fall off and agglomeration of nanoparticles and 2D materials limit a wide range of applications of loose nanofiltration membranes. Furthermore, an expensive raw material and a complicated preparation process of selective layer are huge obstacles to large-scale preparation. In order to improve the permeance, it is often premised on sacrificing the rejection due to the limitations
TABLE 3 | Materials for the separation and recycling of emerging contaminants.

\begin{tabular}{lll}
\hline Materials & Methods & References \\
\hline $\begin{array}{l}\text { Chemical activated } \\
\text { carbon }\end{array}$ & Adsorption & Haroon et al., 2020 \\
$\begin{array}{l}\text { Mesoporous } \\
\text { ion-exchange resin }\end{array}$ & Adsorption & Zhang S. et al., 2020 \\
$\begin{array}{l}\text { PAN-PVA nanofibrous } \\
\text { composite membranes }\end{array}$ & Adsorption & Liu et al., 2020 \\
$\begin{array}{l}\text { PES/TTP nanofiltration } \\
\text { membranes }\end{array}$ & $\begin{array}{l}\text { Aperture Screening and } \\
\text { Donan Effect }\end{array}$ & Moradi et al., 2020 \\
\hline
\end{tabular}

of the traditional trade-off of the membranes. Consequently, it is crucial to develop a simple and cheap membrane preparation method to achieve large-scale applications. Based on this, how to break the limitations of the traditional trade-off is also a problem that needs to be further solved in the preparation of loose nanofiltration membranes.

\section{SEPARATION AND RECYCLING OF EMERGING CONTAMINANTS}

Emerging contaminants refer to all pollutants produced in the production and construction or other activities that do exist at present, but which have not been stipulated by environmental protection laws and regulations or have imperfect regulations and endanger the life and ecological environment. Heavy metals are a class of Endocrine Disrupting Chemicals (EDCs), which are the main components of emerging contaminants. Therefore, from the perspective of environmental protection, it is very important to separate and recycle the heavy metal. Some of the separations of heavy metal ions are briefly summarized in Table 3 .

Traditional separation technologies mainly include ozone oxidation, activated carbon adsorption, evaporation recovery, ion exchange, and the combination of all (Beszedits Stephen, 1980; Haroon et al., 2020; Zhang S. et al., 2020). However, these traditional separation technologies exhibit many disadvantages such as high energy consumption, adsorbent life and adsorption capacity, secondary pollution, etc. (Huang et al., 2020). Based on this, it is very crucial to develop some simple and saving energy technologies. Emerging membrane separation technologies are expected to be a candidate for the treatment of heavy metal ions due to a low energy consumption, a small footprint, a high degree of automation, and a simple operation. Recently, in this area, membrane separation technologies gradually are concerned. Examples include Liu et al. (2020) who observed that polyacrylonitrile- (PAN-) polyvinyl alcohol (PVA) nanofibrous composite membranes demonstrate excellent removal of $\mathrm{Cr}$ (VI) and Cd (II). Similarly, Moradi et al. (2020) introduced a tetrathioterephthalate filler into the polyethersulfone (PES) substrates to prepare effective removal of metal ion membranes. Furthermore, polyamide (PA) nanofiltration membranes synthesized by interfacial polymerization demonstrate excellent performance for water permeance (about $10 \mathrm{~L} / \mathrm{MHB}$ ) and heavy metal ion rejection (about 90\%). However, these kinds of 
membranes are only at the laboratory level. It is very difficult to achieve a large-scale preparation without loss of the performance of membranes. As for plant scale membranes, commercial DuraMem membranes, molecular weight cut-off (MWCO) of about $200 \mathrm{~g} / \mathrm{mol}$, are suitable for the separation and recycling of heavy ions. Although commercial membranes can achieve a large-scale preparation and an effective pollutant rejection, severe permeance limits its extensive application and induces a sharp increase in costs. Trade-off phenomenon (a mutual inhibition of permeance and rejection) has been a main obstacle to a wide application of membranes. In recent years, many researches have been devoted to break the traditional tradeoff limit and achieve excellent results such as mixed-matrix membranes (an increase of solvent permeation channels) and independent preparation of selective layer (reducing roughness and improving solvent affinity). However, these membrane preparation methods are very difficult to achieve commercial large-scale preparations, and the raw materials involved in the membrane synthesis process are very expensive. Therefore, how to break the traditional trade-off phenomenon and realize large-scale production (by simplifying the preparation process and reducing the preparation cost) simultaneously is an urgent problem to be solved at this stage, which is of great significance for energy conservation and economic development.

\section{CONCLUSIONS}

In this stage, traditional separation methods, such as distillation and adsorption, remain the main processing technologies. However, traditional separation technologies need to be improved or replaced because of problems such as the consumption of high energy and the life of an adsorbent.
Emerging membrane separation technologies can solve these problems but a widespread application of these technologies is limited because of membrane factors (heat resistance, corrosion resistance, pollution resistance, long-term stability, etc.) and environmental factors (composition of the applied chemical mixture and the compatibility of the membrane with the process, etc.). Although there is a large amount of research devoted to solving the abovementioned factors of the membrane itself, it is difficult for these research results to expand from laboratory scale to industrial scale, which is because in the process of preparing membranes, performance is often pursued, and the complication of the preparation process and an increase in the preparation cost are ignored. Even if it can be industrialized, once the membrane module is applied to the actual project, the life of the membrane is often greatly reduced due to harsh environmental conditions, thereby increasing the cost, which makes many companies to continue to use traditional separation technologies. Therefore, changing the research thinking is strongly recommended. Researchers should not only focus on the performance of the membrane, but also should design and develop a new type of membrane module from a comprehensive perspective of performance, cost, and process. In the case of a simple preparation process at low cost, even if the performance of the membrane is reduced, as long as there is a little improvement over the previous research, it is very excellent. Numerous small advances will eventually promote large-scale applications of a membrane separation technology.

\section{AUTHOR CONTRIBUTIONS}

The author confirms being the sole contributor of this work and has approved it for publication.

\section{REFERENCES}

Adewole, J., Ahmad, A., Ismail, S., and Leo, C. (2013). Current challenges in membrane separation of $\mathrm{CO}_{2}$ from natural gas: a review. Int. J. Greenhouse Gas Control 17, 46-65. doi: 10.1016/j.ijggc.2013.04.012

Beszedits and Stephen (1980). Removal of Heavy Metals From Wastewaters. B and L Information Services.

Cheng, X., Ding, S., Guo, J., Zhang, C., Guo, Z., and Shao, L. (2017). In-situ interfacial formation of $\mathrm{TiO}_{2}$ /polypyrrole selective layer for improving the separation efficiency towards molecular separation. J. Membr. Sci. 536, 19-27. doi: 10.1016/j.memsci.2017.04.057

Crini, G., and Badot, P. M. (2008). Application of chitosan, a natural aminopolysaccharide, for dye removal from aqueous solutions by adsorption processes using batch studies: a review of recent literature. Prog. Polym. Sci. 33, 399-447. doi: 10.1016/j.progpolymsci.2007.11.001

Cseri, L., Razali, M., Pogany, P., and Szekely, G. (2018). Organic solvents in sustainable synthesis and engineering. Green Chem. 513-553. doi: 10.1016/B978-0-12-809270-5.00020-0

Cuperus, F., and Smolders, C. (1991). Characterization of UF membranes: membrane characteristics and characterization techniques. $A d v$. Colloid Interface Sci. 34, 135-173. doi: 10.1016/0001-8686(91)80 049-P

Feng, X., Nejati, S., Cowan, M. G., Tousley, M. E., Wiesenauer, B. R., Noble, R. D., et al. (2016). Thin polymer films with continuous vertically aligned $1 \mathrm{~nm}$ pores fabricated by soft confinement. ACS Nano 10, 150-158. doi: 10.1021/acsnano.5b06130

Gao, T., Wu, H., Tao, L., Qu, L., and Li, C. (2018). Enhanced stability and separation efficiency of graphene oxide membranes in organic solvent nanofiltration. J. Mater. Chem. 6, 19563-19569. doi: 10.1039/C8TA07147K

Gorham, E. (1991). Northern peatlands: role in the carbon cycle and probable responses to climatic warming. Ecol. Appl. 1, 182-195. doi: 10.2307/1941811

Haroon, H., Shah, J. A., Khan, M. S., Alam, T., Khan, R., Asad, S. A., et al. (2020). Activated carbon from a specific plant precursor biomass for hazardous $\mathrm{Cr}(\mathrm{VI})$ adsorption and recovery studies in batch and column reactors: isotherm and kinetic modeling. J. Water Process. Eng. 38:101577. doi: 10.1016/j.jwpe.2020.101577

Haszeldine, R. S. (2009). Carbon capture and storage: how green can black be? Ence 325, 1647-1652. doi: 10.1126/science.1172246

Huang, J. H., Cheng, X. Q., Zhang, Y., Wang, K., Liang, H., Wang, P., et al. (2020). Polyelectrolyte grafted MOFs enable conjugated membranes for molecular separations in dual solvent systems. Cell Rep. Phys. Sci. 1:100034. doi: $10.1016 /$ j.xcrp.2020.100034

Jiang, X., Li, S., Bai, Y., and Shao, L. (2019). Ultra-facile aqueous synthesis of nanoporous zeolitic imidazolate framework membranes for hydrogen purification and olefin/paraffin separation. J. Mater. Chem. A 7, 10898-10904. doi: 10.1039/c8ta11748a

Jimenez-Solomon, M. F., Song, Q., Jelfs, K. E., Munoz-Ibanez, M., and Livingston, A. G. (2016). Polymer nanofilms with enhanced microporosity by interfacial polymerization. Nat. Mater. 15, 760-767. doi: 10.1038/nmat4638

Kandisa, R. V., Kv, N. S., Shaik, K. B., and Gopinath, R. (2016). Dye removal by adsorption: a review. J. Biorem. Biodegrad. 2016, 1-4. doi: $10.4172 / 2155-6199.1000371$ 
Kang, X., Shuai, L., Xiaomao, W., Chunsheng, C., and Xia, H. (2018). Current state and challenges of full-scale membrane bioreactor applications: a critical review. Bioresour. Technol. 271, 473-481. doi: 10.1016/j.biortech.2018.09.061

Kasimir-Klemedtsson, Å., Klemedtsson, L., Berglund, K., Martikainen, P., Silvola, J., and Oenema, O. (2010). Greenhouse gas emissions from farmed organic soils: a review. Soil Use Manage. 13, 245-250. doi: 10.1111/j.1475-2743.1997.tb00595.x

Katheresan, V., Kansedo, J., and Lau, S. Y. (2018). Efficiency of various recent wastewater dye removal methods: a review. J. Environ. Chem. Eng. 6, 4676-4697. doi: 10.1016/j.jece.2018.06.060

Khalilpour, R., Mumford, K., Zhai, H., Abbas, A., Stevens, G., and Rubin, E. S. (2015). Membrane-based carbon capture from flue gas: a review. J. Clean. Prod. 103, 286-300. doi: 10.1016/j.jclepro.2014.10.050

Koros, W. J., and Lively, R. P. (2012). Water and beyond: expanding the spectrum of large-scale energy efficient separation processes. AIChE J. 58, 2624-2633. doi: 10.1002/aic. 13888

Lee, K. P., Arnot, T. C., and Mattia, D. (2011). A review of reverse osmosis membrane materials for desalination-Development to date and future potential. J. Membr. Sci. 370, 1-22. doi: 10.1016/j.memsci.2010.12.036

Li, J., and Chen, B. (2005). Review of $\mathrm{CO}_{2}$ absorption using chemical solvents in hollow fiber membrane contactors. Sep. Purif. Technol. 41, 109-122. doi: 10.1016/j.seppur.2004.09.008

Lin, J., Ye, W., Zeng, H., Yang, H., Shen, J., Darvishmanesh, S., et al. (2015). Fractionation of direct dyes and salts in aqueous solution using loose nanofiltration membranes. J. Membr. Sci. 477, 183-193. doi: 10.1016/j.memsci.2014.12.008

Liu, X., Jiang, B., Yin, X., Ma, H., and Hsiao, B. S. (2020). Highly permeable nanofibrous composite microfiltration membranes for removal of nanoparticles and heavy metal ions. Sep. Purif. Technol. 233:115976. doi: 10.1016/j.seppur.2019.115976

Liu, Z., Wang, W., Xie, R., Ju, X.-J., and Chu, L.-Y. (2016). Stimuliresponsive smart gating membranes. Chem. Soc. Rev. 45, 460-475. doi: 10.1039/C5CS00692A

Lively, R. P., and Sholl, D. S. (2017). From water to organics in membrane separations. Nat. Mater. 16:276. doi: 10.1038/nmat4860

Moradi, G., Zinadini, S., and Rajabi, L. (2020). Development of the tetrathioterephthalate filler incorporated PES nanofiltration membrane with efficient heavy metal ions rejection and superior antifouling properties. J. Environ. Chem. Eng. 8:104431. doi: 10.1016/j.jece.2020.104431

Quadrelli, R., and Peterson, S. (2007). The energy-climate challenge: recent trends in CO_2 emissions from fuel combustion. Energy Policy 35, 5938-5952. doi: 10.1016/j.enpol.2007.07.001

Rochelle, G. T. (2009). Amine scrubbing for $\mathrm{CO}_{2}$ capture. Science 325, 1652-1654. doi: 10.1126/science.1176731

Rochkind, M., Pasternak, S., and Paz, Y. (2015). Using dyes for evaluating photocatalytic properties: a critical review. Molecules 20, 88-110. doi: 10.3390/molecules20010088

Rundquist, E. M., Pink, C. J., and Livingston, A. G. (2012). Organic solvent nanofiltration: a potential alternative to distillation for solvent recovery from crystallisation mother liquors. Green Chem. 14, 2197-2205. doi: 10.1039/C2GC35216H

Sholl, D. S., and Lively, R. P. (2016). Seven chemical separations to change the world. Nature 532, 435-437. doi: 10.1038/532435a

Striemer, C. C., Gaborski, T. R., Mcgrath, J. L., and Fauchet, P. M. (2007). Charge-and size-based separation of macromolecules using ultrathin silicon membranes. Nature 445, 749-753. doi: 10.1038/nature05532
Vreese, I. D., and Bruggen, B. V. D. (2007). Cotton and polyester dyeing using nanofiltered wastewater. Dyes Pigm. 74, 313-319. doi: 10.1016/j.dyepig.2006.02.014

Wang, L., Wang, N., Zhang, G., and Ji, S. (2013). Covalent crosslinked assembly of tubular ceramic-based multilayer nanofiltration membranes for dye desalination. AIChE J. 59, 3834-3842. doi: 10.1002/aic.14093

Wang, X., Fang, D., Yoon, K., Hsiao, B. S., and Chu, B. (2006). High performance ultrafiltration composite membranes based on poly (vinyl alcohol) hydrogel coating on crosslinked nanofibrous poly (vinyl alcohol) scaffold. J. Membr. Sci. 278, 261-268. doi: 10.1016/j.memsci.2005.11.009

Wang, Y., Ma, X., Ghanem, B., Alghunaimi, F., Pinnau, I., and Han, Y. (2018). Polymers of intrinsic microporosity for energy-intensive membrane-based gas separations. Mater. Today 3, 69-95. doi: 10.1016/j.mtnano.2018.11.003

Wang, Z., Yang, H.-C., He, F., Peng, S., Li, Y., Shao, L., et al. (2019). Mussel-inspired surface engineering for water-remediation materials. Matter 1, 115-155. doi: 10.1016/j.matt.2019.05.002

Wang, Z., Yao, X., and Wang, Y. (2012). Swelling-induced mesoporous block copolymer membranes with intrinsically active surfaces for size-selective separation. J. Mater. Chem. 22, 20542-20548. doi: 10.1039/C2JM34292H

Xiang, S., He, Y., Zhang, Z., Wu, H., Zhou, W., Krishna, R., et al. (2012). Microporous metal-organic framework with potential for carbon dioxide capture at ambient conditions. Nat. Commun. 3:954. doi: 10.1038/ncomms 1956

Yang, Q., Su, Y., Chi, C., Cherian, C. T., Huang, K., Kravets, V. G., et al. (2017). Ultrathin graphene-based membrane with precise molecular sieving and ultrafast solvent permeation. Nat. Mater. 16, 1198-1202. doi: $10.1038 /$ nmat5025

Yang, X., Sun, P., Zhang, H., Xia, Z., Waldman, R. Z., Mane, A. U., et al. (2020). Polyphenol-sensitized atomic layer deposition for membrane interface hydrophilization. Adv. Funct. Mater. 30:1910062. doi: 10.1002/adfm.201910062

$\mathrm{Ze}, \mathrm{Z}$., and Sx, J. (2014). Hollow fiber membrane contactor absorption of $\mathrm{CO}_{2}$ from the flue gas: review and perspective. Glob. Nest J. 16, 355-374.

Zhang, J., Li, Z., Zhan, K., Sun, R., Sheng, Z., Wang, M., et al. (2019). Two dimensional nanomaterial-based separation membranes. Electrophoresis 40, 2029-2040. doi: 10.1002/elps.201800529

Zhang, S., Ning, S., Liu, H., Wang, X., Wei, Y., and Yin, X. (2020). Preparation of ion-exchange resin via in-situ polymerization for highly selective separation and continuous removal of palladium from electroplating wastewater. Sep. Purif. Technol. 258:117670. doi: 10.1016/j.seppur.2020.117670

Zhang, Y., Ma, J., and Shao, L. (2020). Ultra-thin trinity coating enabled by competitive reactions for unparalleled molecular separations. J. Mater. Chem. A 8, 5078-5085. doi: 10.1039/C9TA12670H

Zhu, J., Tian, M., Hou, J., Wang, J., Lin, J., Zhang, Y., et al. (2016). Surface zwitterionic functionalized graphene oxide for a novel loose nanofiltration membrane. J. Mater. Chem. A 4, 1980-1990. doi: 10.1039/C5TA0 $8024 \mathrm{~J}$

Conflict of Interest: The author declares that the research was conducted in the absence of any commercial or financial relationships that could be construed as a potential conflict of interest.

Copyright (C) 2020 Shao. This is an open-access article distributed under the terms of the Creative Commons Attribution License (CC BY). The use, distribution or reproduction in other forums is permitted, provided the original author(s) and the copyright owner(s) are credited and that the original publication in this journal is cited, in accordance with accepted academic practice. No use, distribution or reproduction is permitted which does not comply with these terms. 